\title{
Comparison of Large-bore Intercostal Catheter and Small-Bore Ambulatory Pleural Drain in the Management of Pleural Effusion
}

\author{
Ekpe E.E. ${ }^{* 1}$, Uduma F. ${ }^{2}$, Umoh V. ${ }^{3}$, Ikpe MC. ${ }^{2}$, Eyo C. ${ }^{4}$, Akpan AF. ${ }^{1}$ \\ ${ }^{1}$ Cardiothoracic Surgery Unit, Department of Surgery, University of Uyo, Nigeria \\ ${ }^{2}$ Department of Radiology, University of Uyo, Nigeria \\ ${ }^{3}$ Respiratory Medicine Unit, Department of Internal Medicine, University of Uyo, Nigeria \\ ${ }^{4}$ Department of Anaesthesia, University of Uyo, Nigeria
}

*Corresponding Author: Dr. Ekpe, Eyo Effiong; eyoekpe@ uniuyo.edu.ng

Received 04 May 2019;

Accepted 16 May 2019;

Published 31 May 2019

\begin{abstract}
Background: The use of conventional chest tube and underwater seal bottle (CCT) for pleural drainage (PD) makes the treatment expensive, immediately un-affordable by more than $80 \%$ of the patients in Nigeria, and also immobilizes the patients with the attendant risks. To curtail the above mentioned problems, some researchers have reported the use of one-way valve and drainage bag for PD. Objective: To evaluate and compare PD using urobag versus CCT. Methodology: Prospective randomized study of adult patients with pleural effusion who had PD with CCT and urobag respectively. Results: Before PD and at 30 minutes into the drainage, no patient in the two groups had normal respiratory rate (RR), but by 30 minutes before removal of the pleural drain, $80.5 \%$ in the CCT group and $69.2 \%$ in the urobag group had achieved normal RR. And by the 30 days follow up assessment, $100 \%$ in both groups maintained normal $R R(p=0.459)$. The equivalent figures evaluating the patients for peripheral arterial oxygen saturation showed subnormal saturation in all patients in the two groups at 30 minutes before PD, normal saturation in $22 \%$ of patients in CCT group versus zero percent in the urobag group at 30 minutes after commencement of PD (p<0.0001). At 30 minutes before removal of pleural drain saturation was normal in $97.6 \%$ of the CCT and $84.6 \%$ of the urobag group. By 30 days follow up, oxygen saturation became normal in $97.6 \%$ of CCT group versus $100 \%$ of urobag group. Lung expansion assessed with chest radiographs at 30 minutes after pleural drainage $46.3 \%$ in the CCT group versus $53.8 \%$ in the urobag group had complete lung expansion. These figures rose to $97.6 \%$ and $100 \%$ respectively at 30 minutes before removal of pleural drain and at 30 days follow-up ( $\mathrm{p}=0.823$ ). Duration of drainage of pleural effusion was less than 7 days in $92.7 \%$ of patients on CCT and in $92.3 \%$ of the urobag group. Length of hospital stay analysis showed that length of stay was shorter than 10 days in $97.6 \%$ and $100 \%$ of the CCT and urobag groups respectively. Complications attributable to the drainage systems were negligible. Conclusion: Pleural drainage with urobag and CCT all result in acceptable outcome of drainage.
\end{abstract}

Keywords: Chest tube, Pleural drainage, Underwater seal bottle, Urobag

\section{Introduction}

Pleural drainage (PD) is a life-saving and frequently performed procedure in hospitals where the expertise and necessary tools are available to prevent possible complications like infection and respiratory compromise. ${ }^{[1-4]}$ The presence of air, blood or fluids in the thoracic cavity counters the negative pressure within the pleural space and causes pulmonary collapse. In order to promote adequate lung expansion, as well as to re-establish cardio-respiratory function and negative intra-pleural pressure, ${ }^{[5]}$ thoracic trauma and many pleural disease are commonly treated with tube thoracostomy. ${ }^{[1-3]}$ The function of chest tubes is dependent on adequacy of placement, effectiveness of drainage and frequency of re-evaluation of the patients and the chest drainage system. Therefore knowledge of the principles of chest tube drainage is important to evaluate adequately the function of $\mathrm{PD} .{ }^{[6]} \mathrm{Up}$ to $85 \%$ of thoracic trauma would not need any more major surgical intervention than PD. This shows how important PD is when one considers that thoracic trauma alone accounts for about $50 \%$ of trauma-related deaths. ${ }^{[7]}$

PD can be done either surgically or percutaneously and indications include therapeutic drainage of pleural conditions such as pleural effusion, pneumothorax, haemothorax, chylothorax, and malignant effusions, as well as prophylaxis drainage of air, blood, and other fluids after chest surgery. ${ }^{[8-12]}$ The conventional system of PD 
currently in use is the same as that described by Kenyon in $1916 .^{[13]}$ This method consists of inserting the distal extremity of the chest tube into a liquid column, contained inside a flask called chest tube drainage bottle, whose cap has two openings: one for the passage of the chest tube and one for ventilation (air vent). This is known as a water-seal drainage system. The use of this system in the postoperative period following thoracic surgery was described and disseminated by Lilienthal in $1922 .^{[14]}$

This system is efficient and safe but expensive. However, using these chest tube drainage bottles might cause risks, disadvantages and inconveniences for patients: they are heavy and large; they restrict the mobility of patients; ${ }^{[15]}$ frequent clamping performed during transport might cause pulmonary collapse and formation of clots, ${ }^{[15]}$ as well as tension pneumothorax; the placement of the chest tube drainage bottles, always kept in a level below the thorax of the patient, facilitates the disconnection of one of the connections; and the bubbling inside the chest tube drainage bottle, when connected to continuous suction, causes as unpleasant sound ${ }^{[16]}$ It is also to be emphasized that using this method in a pre-hospital environment is inappropriate, because it is not only difficult to keep the chest tube drainage bottle below the patient, but it is also necessary to perform frequent clamping inside the limited space of an ambulance. ${ }^{[15]}$

In 1968, Henry Heimlich idealized a one-way valve device in order to replace underwater seal drainage systems. The following advantages of the one-way valve device were described: it provide better mobility of patients; clamping is unnecessary during transportation; the valves keeps working regardless of its position or level; nursing and medical teams can easily understand how it works; and it is safer and easier to clean.17 Since then, interest in developing an alternative and adequate thoracic drainage system has been reported in the literature. ${ }^{[16,18-24]}$ In Nigeria Aldon's drainage bags have been used in a centre without objective comparison with chest tube and underwater seal drainage system. ${ }^{[2,23]}$ Urobag has one-way valve which satisfy its suitability for PD. The cost of a chest tube and the chest tube drainage bottle in Nigeria currently is about seventeen thousand naira (N17,000) which is high for most Nigerians who may require PD as an emergency procedure. In comparison the cost of an urobag is about five hundred naira (N500). The aim of this study is to evaluate PD using an urobag for the treatment of pleural effusion and compare with the performance of conventional chest tube connected to underwater seal bottle.

\section{Patients and methods}

The study is a prospectively randomized study to compare plural effusion drainage using an urobag, conventional chest tubes connected to urobag and conventional chest tubes (thoracic catheters) connected to an underwater seal bottle. Ethical approval was obtained from the institutional health research ethics board.

Appropriate consented patients who were diagnosed to have nonmalignant pleural effusion (such as post pneumonic pleural effusion, pleural tuberculosis, and HIV-associated pleural effusion), haemothorax, pneumothorax or pneumo-haemothorax were randomized into the three groups for study as follows:

Group 1 patients: underwent $\mathrm{PD}$ using size $28 \mathrm{Fr}$ gauge conventional chest tubes (thoracic catheters) connected to an underwater seal bottle [CCT] figure 1 .

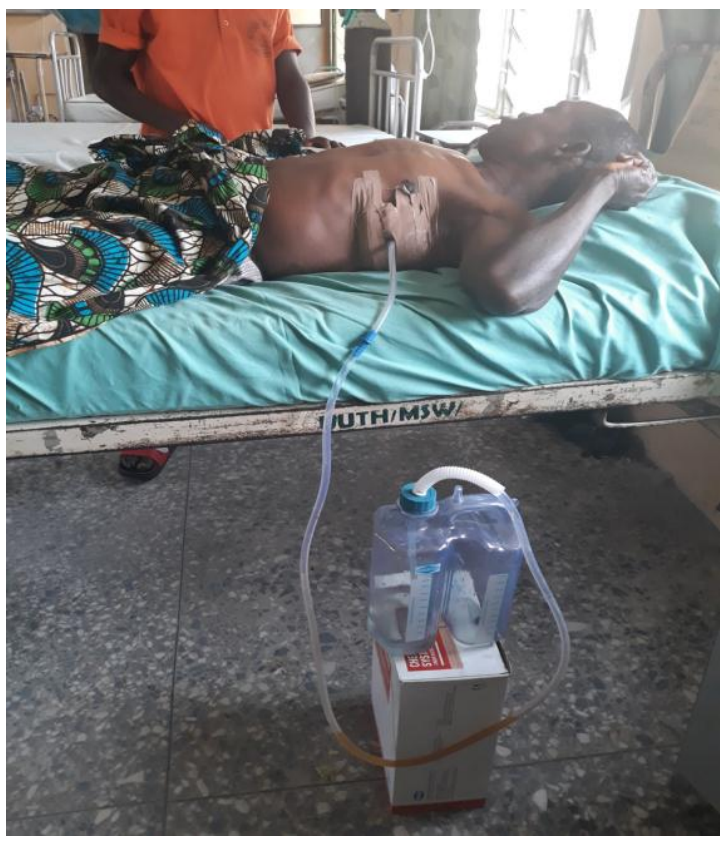

Figure 1: Drainage of left sided pleural effusion using conventional chest tube connected to underwater seal bottle

Group 2 patients: underwent PD using the tubing of urobag attached to the drainage bag. This qualifies for small-bore tube because it is equivalent to size $15 \mathrm{Fr}$ gauge. The urobag used was the Medihel Urine bag (Anhui Medihel Co. Ltd, China) which has a tubing length of $85 \mathrm{~cm}$ long and external diameter of $5 \mathrm{~mm}(15 \mathrm{Fr})$. The tube is attached to a two litre capacity collapsible bag across a one-way flutter valve. Figure 2

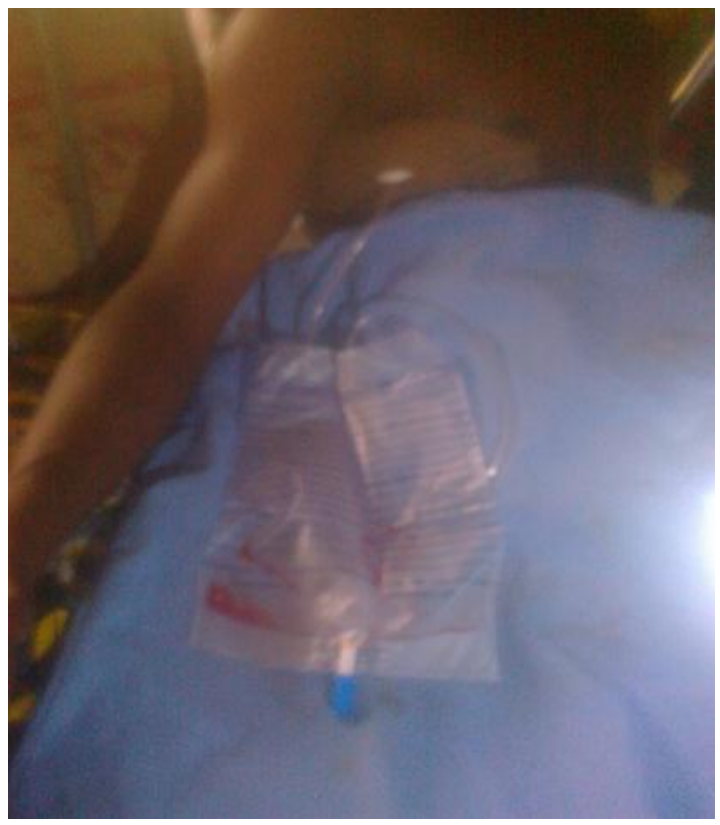

Figure 2: Drainage of right sided pleural effusion using urobag

Group 3 patients: underwent PD using size $28 \mathrm{Fr}$ gauge conventional chest tubes (thoracic catheters) connected to drainage bag.

All cases of massive pleural effusion had intermittent clamping/unclamping for drainage of $100-200 \mathrm{ml}$ of pleural fluid every hour to prevent acute re-expansion pulmonary oedema. The 30 minutes measurement was from when the accumulated pleural effusion was drained, that is the drainage was no longer under pressure; and not necessarily 30 minutes from insertion of the pleural drain. 
This analysis is only on the patients that had pleural effusion and had PD with either CCT or urobag.

Outcome measures were respiratory rate, peripheral arterial oxygen saturation (SpO2), lung re-expansion, duration of the drainage, length of hospital stay, and any observed complications. Assessment of respiratory rate and $\mathrm{SpO} 2$ were at 30 minutes before PD, 30 minutes following evacuation of accumulated pleural effusion, 30 minutes before removal of chest drain and 30 days after discharge. The peripheral arterial oxygen saturation considered normal was $\mathrm{SpO} 2 \geq 95 \%$. Each patient was submitted to chest X-rays for diagnosis, in the 30 minutes post chest tube insertion period, before removal of the chest tube and during the 30-day outpatient follow-up. And lung expansion was assessed in the post procedure and follow-up chest radiographs.

Complications considered in this study were complications related to the PD system such as tube obstruction due to blood/fibrin clots, preventing fluids from flowing out of the thoracic cavity, tube collapse preventing fluids from flowing out of the thoracic cavity, dislodgement/displacement of the tube from pleural cavity and disconnection of tube from the drainage bottle.

The relationship between variables were analysed using Fisher's exact test. Statistical tests were subjected to assumption testing to determine their data fitness. Using a two tailed-test, a P-value of < 0.05 and $95 \%$ confidence level were considered significant. Statistical analysis was performed using STATA Version 12 (StataCorp www.stata.com)

\section{Results}

Table 1: Socio-demograhic characteristics of the respondents

\begin{tabular}{|c|c|c|c|c|}
\hline \multirow[t]{2}{*}{ Characteristics } & \multicolumn{2}{|l|}{$\operatorname{Sex} n(\%)$} & \multirow[t]{2}{*}{ Total $(n=100)$} & \multirow[t]{2}{*}{ Statistical indices } \\
\hline & Male $(n=44)$ & Female $(n=56)$ & & \\
\hline $\begin{array}{l}\text { Age group } \\
\text { Less than } 20 \\
20-29 \\
30-39 \\
40-49 \\
50-59 \\
60-69 \\
70 \text { and above }\end{array}$ & $\begin{array}{l}3(6.8) \\
7(15.9) \\
11(25.0) \\
10(22.7) \\
5(11.4) \\
6(13.6) \\
2(4.6)\end{array}$ & $\begin{array}{l}3(5.4) \\
5(8.9) \\
14(25.0) \\
12(21.4) \\
10(17.9) \\
8(14.3) \\
4(7.1)\end{array}$ & $\begin{array}{l}6(6.0) \\
12(12.0) \\
25(25.0) \\
22(22.0) \\
15(15.0) \\
14(14.0) \\
6(6.0)\end{array}$ & $\begin{array}{l}x^{2}=2.0842 \\
D f=6 \\
P \text { value }=0.912\end{array}$ \\
\hline $\begin{array}{l}\text { Marital status } \\
\text { Single } \\
\text { Married } \\
\text { Widowed }\end{array}$ & $\begin{array}{l}29(65.9) \\
15(34.1) \\
0(0.0)\end{array}$ & $\begin{array}{l}49(75.0) \\
12(21.4) \\
2(3.6)\end{array}$ & $\begin{array}{l}71(71.0) \\
27(27.0) \\
2(2.0)\end{array}$ & $\begin{array}{l}x^{2}=2.0842 \\
D f=2 \\
P \text { value }=0.190\end{array}$ \\
\hline $\begin{array}{l}\text { Occupation } \\
\text { Civil servant } \\
\text { Self employed } \\
\text { Student } \\
\text { Applicants } \\
\text { Retired }\end{array}$ & $\begin{array}{l}10(22.7) \\
19(43.2) \\
8(18.2) \\
1(2.3) \\
6(13.6)\end{array}$ & $\begin{array}{l}10(17.9) \\
30(53.6) \\
6(10.7) \\
2(3.0) \\
8(14.3)\end{array}$ & $\begin{array}{l}20(20.0) \\
49(49.0) \\
14(14.0) \\
3(3.0) \\
14(14.0)\end{array}$ & $\begin{array}{l}x^{2}=1.9624 \\
\mathrm{Df}=3 \\
P \text { value }=0.743\end{array}$ \\
\hline $\begin{array}{l}\text { Types of intervention } \\
\text { Conventional under water seal (CCT) } \\
\text { Conventional with Urobag } \\
\text { Urobag only }\end{array}$ & $\begin{array}{l}24(54.5) \\
14(31.8) \\
6(13.6)\end{array}$ & $\begin{array}{l}36(64.3) \\
6(10.7) \\
14(25.0)\end{array}$ & $\begin{array}{l}60(60.0) \\
20(20.0) \\
20(20.0)\end{array}$ & $\begin{array}{l}x^{2}=7.4675 \\
D f=2 \\
P \text { value }=0.028+\end{array}$ \\
\hline $\begin{array}{l}\text { Diagnoses } \\
\text { Pleural effusion } \\
\text { Heamothorax } \\
\text { Pneumothorax } \\
\text { Heamopnuemothorax } \\
\text { Chylothorax }\end{array}$ & $\begin{array}{l}31(70.5) \\
4(9.1) \\
6(13.6) \\
3(6.8) \\
0(0.0)\end{array}$ & $\begin{array}{l}38(67.9) \\
8(14.3) \\
5(8.9) \\
3(5.4) \\
2(3.6)\end{array}$ & $\begin{array}{l}69(69.0) \\
12(12.0) \\
11(11.0) \\
6(6.0) \\
2(2.0)\end{array}$ & $\begin{array}{l}x^{2}=2.733 \\
\mathrm{Df}=4 \\
\mathrm{P} \text { value }=0.603\end{array}$ \\
\hline
\end{tabular}

Table 2: Comparison of proportion of respondents with pleural effusion who recovered after CCT and Urobag interventions

\begin{tabular}{|l|l|l|l|l|}
\hline Characteristics & CCT $(\mathbf{n = 4 1})$ & Urobag $(\mathbf{n = 1 3})$ & Total $(\mathbf{n = 5 4})$ & P value \\
\hline $\begin{array}{l}\text { Respiratory rate } \\
30 \text { minutes before chest tube drainage }\end{array}$ & $0(0.0)$ & $0(0.0)$ & $0(0.0)$ & \\
$\begin{array}{l}\text { Normal } \\
30 \text { minutes after chest tube }\end{array}$ & $0(0.0)$ & $0(0.0)$ & $0(0.0)$ & \\
$\begin{array}{l}\text { Normal } \\
30 \text { minutes Before removal of chest tube } \\
\text { Normal } \\
30 \text { days after removal } \\
\text { Normal }\end{array}$ & $33(80.5)$ & $9(69.2)$ & $13(100.0)$ & $54(100.0)$ \\
\hline $\mathrm{SpO}_{2}(\%)$ & $41(100.0)$ & & & \\
\hline
\end{tabular}




\begin{tabular}{|c|c|c|c|c|}
\hline $\begin{array}{l}30 \text { minutes before chest tube drainage } \\
\text { Normal } \\
30 \text { minutes after chest tube drainage } \\
\text { Normal } \\
30 \text { minutes before removal } \\
\text { Normal } \\
30 \text { days after removal } \\
\text { Normal }\end{array}$ & $\begin{array}{l}0(0.0) \\
9(22.0) \\
40(97.6) \\
40(97.6)\end{array}$ & $\begin{array}{l}0(0.0) \\
0(0.0) \\
11(84.6) \\
13(100.0)\end{array}$ & $\begin{array}{l}0(0.0) \\
9(16.7) \\
51(98.1) \\
53(98.1)\end{array}$ & $<0.0001$ \\
\hline $\begin{array}{l}\text { Lung expansion } \\
30 \text { minutes before chest tube drainage } \\
\text { Normal } \\
30 \text { minutes after chest tube drainage } \\
\text { Normal } \\
30 \text { minutes before removal } \\
\text { Normal } \\
30 \text { days after removal } \\
\text { Normal }\end{array}$ & $\begin{array}{l}0(0.0) \\
19(46.3) \\
40(97.6) \\
40(97.6)\end{array}$ & $\begin{array}{l}0(0.0) \\
7(53.8) \\
13(100.0) \\
13(100.0)\end{array}$ & $\begin{array}{l}0(0.0) \\
26(43.1) \\
53(98.1) \\
53(98.1)\end{array}$ & 0.823 \\
\hline $\begin{array}{l}\text { Duration of drainage } \\
\text { Less than } 7 \text { days } \\
7 \text { days }\end{array}$ & $\begin{array}{l}38(92.7) \\
3(7.3)\end{array}$ & $\begin{array}{l}12(92.3) \\
1(7.7)\end{array}$ & $\begin{array}{l}50(92.6) \\
4(7.4)\end{array}$ & 1.000 \\
\hline $\begin{array}{l}\text { Length of Hospital stay } \\
\text { Less than } 10 \text { days } \\
10 \text { days }\end{array}$ & $\begin{array}{l}40(97.6) \\
1(2.4)\end{array}$ & $\begin{array}{l}13(100.0) \\
0(0.0)\end{array}$ & $\begin{array}{l}53(98.2) \\
1(1.8)\end{array}$ & 1.000 \\
\hline
\end{tabular}

One hundred patients with mean age $43.8( \pm 15.9)$ who underwent PD were studied consisting of 44 males and 56 females (male female ratio=1:1.3). Mean age of males was lower than that of females $(41.6( \pm 15.9)$ versus $45.4( \pm 15.9)$ but with no statistically significant difference $(\mathrm{P}=0.24)$. Young and middle aged adults constituted $74 \%$ of the patients and the frequency in the age stratification was approximate among the two sexes with no statistical difference (table 1). Majority (69.0\%) of the patients were employed while the remaining $31.0 \%$ consisted of students $(14 \%)$, retired workers $(14 \%$,$) and applicants (3 \%)$. The patients were treated for pleural effusion in $69 \%$, traumatic haemothorax in $12 \%$, spontaneous and traumatic pneumothorax in $11 \%$, traumatic haemopneumothorax in $6 \%$ and chylothorax in $2 \%$. Sixty percent of the patients underwent PD with conventional chest tube connected to under-water seal bottle, $20 \%$ underwent PD with oneway valved urobag, and another $20 \%$ underwent PD with conventional chest tube connected to one-way valved urobag. The last group was not analysed further and this analysis is only on the patients that had pleural effusion and had PD with either CCT or urobag.

Among the patients with pleural effusion, 41 of them were treated with conventional chest tube connected to under-water seal bottle (CCT) while 13 treated with urobag. Before PD and at 30 minutes into the drainage, no patient in the two groups had normal respiratory rate, but by 30 minutes before removal of the pleural drain, $80.5 \%$ in the CCT group and $69.2 \%$ in the urobag group had achieved normal respiratory rate. The difference was not statistically significant $(\mathrm{p}=0.459)$. However by the 30 days follow up assessment, $100 \%$ in both groups maintained normal respiratory rate. The equivalent figures from assessing the patients for $\mathrm{SpO} 2$ showed subnormal saturation in all patients in the two groups 30 minutes before PD, normal saturation in $22 \%$ of patients in CCT group versus zero percent in the urobag group by 30 minutes following commencement of PD. The difference was statistically significant $(p<0.0001)$. And at 30 minutes before removal of pleural drain there was normal saturation in $97.6 \%$ of patents in the CCT group and $84.6 \%$ of the urobag group. However by 30 days follow up, normal saturation was recorded in $97.6 \%$ of CCT group versus $100 \%$ of urobag group. The difference was not statistically significant. Lung volume before PD assessed in the preintervention chest radiograph was partially collapsed in all patients in the two arms of the study. Lung re-expansion assessed at 30 minutes after PD showed $46.3 \%$ in the CCT group versus $53.8 \%$ in the urobag group had complete lung re-expansion. These figures rose to $97.6 \%$ and $100 \%$ respectively at 30 minutes before removal of pleural drain and at 30 days follow-up. The difference was not statistically significant $(\mathrm{p}=0.823)$

Comparison of the duration of PD and length of hospital stay amongst the two arms of treatment showed that drainage was completed within seven days in $92.7 \%$ and beyond seven days in $7.3 \%$ of the CCT group, while length of hospitalisation was less than ten days in $97.6 \%$ and beyond ten days in $2.4 \%$. The equivalent figures in the urobag group were drainage within seven days $(92.3 \%)$ and beyond seven days (7.7\%); and hospital stay less than ten days $(100 \%)$. The differences were not statistically significant $(\mathrm{p}=1.000)$

\section{Discussion}

Large bore chest tubes have external diameter greater $20 \mathrm{Fr}$ gauge while small bore chest tubes are smaller than $20 \mathrm{Fr}$ gauge. ${ }^{[8]}$ The large bore chest tubes are usually connected to underwater seal drainage bottle which represented the CCT group of this study. This system renders the patient relatively immobile with attendant risks of development of deep vein thrombosis, pulmonary embolism and sudden death, ${ }^{[21]}$ whereas the small bore chest drains are attached to ambulatory drainage bag (Urobag group of this study) and avoids the risks of immobilisation but still offers comparable efficacy. ${ }^{[21]}$ However the drawbacks of using urobag as pleural drain include the potential for accidental dislodgement [which can be prevented by a more rigorous anchoring of the tube], inability to apply negative pressure suction if necessary, and absence of side fenestrations for enhanced drainage [which have to be created after cutting off the stiff end]. 
In this study, normalisation of respiratory rate was only better in the CCT group at the 30 minutes before removal of chest drain assessment period $(80.5 \%$ versus $69.2 \%)$. Although the difference was not statistically significant $(\mathrm{p}=0.459)$, respiratory rate can be affected by chest pain, anxiety, fever and primary pulmonary disease. At 30 days follow up all patients in the two groups had normal respiratory rate. Previous studies comparing large and small bore pleural drains did not analyse respiratory rate rather looked at effectiveness in terms of duration of drainage and complications. ${ }^{[25,26]}$

Peripheral arterial oxygen saturation (SpO2) showed initial superiority in the CCT group at both 30 minutes following commencement of PD (22.0\% versus $0 \%)$ and at 30 minutes before removal of pleural drain $(97.6 \%$ versus $84.6 \%$ with $\mathrm{p}<0.0001$. However at 30 days follow-up, urobag group was better while the CCT group remained same (100\% versus $97.6 \%)$. SpO2 can be negatively affected by the quality of breathing including the efficiency of gaseous exchange. Therefore the pulmonary conditions that caused the pleural effusion might have a long term effect on pulmonary functions and explains the non-return of $\mathrm{SpO} 2$ in some patients though fully treated for pleural effusion.

Return of complete lung expansion assessed with serial chest radiographs was consistently better in the urobag group at the three reassessment periods $(53.8 \%$ versus $46.3 \%, 100 \%$ versus $97.6 \%$ and $100 \%$ versus $97.6 \%$ respectively). The severity of the lung disease, bronchial blockade and thickened visceral pleura can all affect re-expansion of the lung. Since chest computerised tomographic scan was not done as a routine investigation in this study it was not known why a particular patient in the CCT group had persistent collapsed lung. This aspect of outcome measure has corroborated the study by Fysh et al. ${ }^{[5]}$ The analysis of duration of PD and length of hospitalisation because of pleural effusion among the two treatment groups also proved the acceptability of the two treatment methods. PD was completed in almost all patients $(92.7 \%$ vs $92.3 \%)$ within seven days, while length of hospitalisation was less than 10 days in $97.6 \%$ vs $100 \%$ of patients in the CCT and urobag treatment groups respectively. The short and comparable periods of PD and hospital stay among the two groups has proven that urobag used in this study as ambulatory small-bore pleural drain may be as effective as the large-bore thoracic catheter connected to underwater seal bottle. This has been postulated by previous studies. ${ }^{[1,5,6,8,11,15,16,18-26]}$ At 30 days follow up assessment, $100 \%$ of the patients in the urobag group had normal peripheral arterial oxygen saturation ( $\mathrm{SpO} 2)$ and full lung expansion. The last assessment before pleural drain removal had still shown full lung expansion in all patients in the urobag group but normal $\mathrm{SpO} 2$ in $84.6 \%$. The explanation for this observation include the fact chest pain caused by the presence of insitu pleural drain could make some patients maintain shallow depth of breathing and incomplete aeration of all bronchopulmonary segments and therefore subnormal SpO2 in the few (15.4\%) patients. In the CCT arm, one patient $(2.4 \%)$ persistently had incompletely expanded lung and subnormal $\mathrm{SpO} 2$ at the last assessment before removal of chest tube and during the 30 days follow up assessment. This patient had trapped lung and needed thoracotomy and decortication which the patient was subsequently advised.

Observed complications were negligible among the two treatment groups, and they included two cases of tube obstruction by fibrin clot (one) and collapse (one) in the urobag group and one case of tube disconnection from the drainage bottle in the CCT group.
Superiority of one size of tube over the other could further be substantiated with better designed multicentre research involving larger number of patients especially that it is known that the risks of prolonged immobilisation that exist when PD is done with largebore thoracic catheter connected to underwater seal bottle do not exist with ambulatory small-bore pleural drain utilising urobag.

\section{Conclusion}

Pleural drainage with urobag and CCT all result in acceptable outcome of drainage.

\section{References}

[1] Edaignini SA, Delia IZ, Aminu MB, Orogade AA, Anumenechi N, Aliyu ID, Indictions and complications of tube thoracostomy with improvised underwater seal bottles. Niger J Surg. 2014; 20:79-82.

[2] Kesieme EB, Olusoji O, Inuwa IM, Ngene Cl, Aigbe E. Management of Chest drains: A national survey on surgeons in-training experience and practice. Niger $\mathrm{J}$ Surg. 2015; 21:91-5.

[3] Ekpe EE, Nottidge TE, Akaiso OE. Cardiothoracic Surgical Emergencies in a Niger Delta Tertiary Health Institution: A 12 Month Appraisal. Ibom Medical Journal, 2008; 3:22-29.

[4] Ekpe EE, Eyo C. Determinants of Mortality in Chest Truama Patients. Nigerian Journal of Surgery 2014; 20:30-34.

[5] Fysh ET, Smith NA, Lee YC. Optimal chest drain size: the rise of the small-bore pleural catheter. Semin Respir Crit Care Med. 2010;31:760-8 doi:10.1055/s-00301269836. Epub 2011 Jam 6.

[6] Brandt ML, Luks FI, Lacroix J, Guay J, Collin PP, Dilorenzo M. The paediatric chest tube. Clin Intensive Care. 1994; 5:123-9.

[7] Ekpe EE, Eyo C. Overview of Blunt Chest Injury with Multiple Rid Fractures. British Journal of Medicine \& Medical Research 2016; 12: 1-15.

[8] Cooke DT1, David EA. Large-bore and small-bore chest tubes: types, function, and placement. Thorac Surg Clin. 2013; 23:17-24, v. doi: 10. 1016/j.thorsurg.c012.10.006

[9] Ekpe E.E., Onwuta C. N., Edaigbini S.A., Okwulehie A. V. Catamenial Pneumothrax: Still a Rare Syndrome; Ibom Medical Journal. 2007; 2: 13-16.

[10] Ekpe EE. Akpan MU. Poorly treated broonchopneumonia with progression to empyema thoracis in Nigerian Children. TAF Preventive Medicine Bulletin. 2010;9:181-186.

[11] Ekpe EE, Akpan MU. Outcome of tube thoracostomy in paediatric non-traumatic pleural fluid collections. African J Paediatric Surg. 2012; 10:122-126.

[12] Ekpe EE, Ikpe MC. Extensive interstitial emphysema complicating blunt chest injury. Ibom Medical Journal. 2011;4:11-14.

[13] Lilienthal H. Resection of the lung for suppurative infections with a report based on 31 operative cases in which resection was done or intended. Ann Surg. 1922;75;257-320.

[14] Kenyon JH. Traumatic Hemothorax: siphon drainage. Ann Surg. 1916;64:728-9.

[15] Vaga Nde A, Ortega HA, Tincani AJ, Toro IF. Use of a one-way flutter valve drainage system in the 
postoperative period following lung resection. J Bras Pneumol. 2008; 34:559-66.

[16] VuorisaloS1, Aranio P, Hannukainen J. Comparison between flutter valve drainage bag and underwater seal device for pleural drainage after lung surgery. Scand $\mathbf{J}$ Surg. 2005;94:56-8.

[17] Heimlich HJ. Valve drainage of the pleural cavity. Di chest. 1968;53:282-7.

[18] Waller DA, Edwards JG, Rajesh PB.A physiological comparison of flutter valve drainage bags and underwater seal systems for postoperative air leaks. Thorax. 1999;54:442-3.

[19] Graham AN, Cosgrove AP, Gibbons JR, McGuigan JA. Randomised Clinical trial of chest drainage systems. Thorax. 1992;47:461-2.

[20] Bar-El Y, Lieberman Y, Yellin A. Modified urinary collecting bags for prolonged underwater chest drainage. Ann Thorac Surg. 1992;54:995-6.
[21] Joshi JM. Ambulatory chest drainage. Indian J Chest Dis Allied Sci. 2009; 51:225-31.

[22] Adeboye VO Adebo OAM Osinowo O, Brimmo IA. Closed chest drainage without an underwater seal. Afr J Med Med Sci. 1996; 25:353-5.

[23] Adegboye VO Adebo OA, Brimmo AI. Postoperative closed chest drainage without an underwater seal: a preliminary report. Afr J Mem Med Sci. 1997; 26:1-3.

[24] Ponn RB Silverman HJ, Federico JA. Outpatient chest tube management. Ann Thorac Surg. 1997; 64:1437-40.

[25] Light RW. Pleural controversy: optimal chest tube size for drainage. Respirology. 2011;16:244-8. doi: 10.1111/j.1440-1843.2010.01913.x.

[26] Parulekar W, Di Primio G, Matzinger F. Use of smallbore vs large-bore chest tubes for treatment of malignant pleural effusions. Chest. 2001; 120: 19-25. 